Original Article

\title{
Maternal determinants of immunization status of children aged 12-23 months in urban slums of Varanasi, India
}

\author{
Ashish Awasthi ${ }^{a}$, C.M. Pandey ${ }^{b, *}$, Uttam Singh ${ }^{a}$, Sarvesh Kumar ${ }^{c}$, \\ T.B. Singh ${ }^{d}$ \\ ${ }^{a}$ Department of Biostatistics \& Health Informatics, Sanjay Gandhi Postgraduate Institute of Medical Sciences, \\ Lucknow 226014, India \\ ${ }^{\mathrm{b}}$ Professor and Head, Department of Biostatistics \& Health Informatics, \\ Sanjay Gandhi Postgraduate Institute of Medical Sciences, Lucknow 226014, India \\ ${ }^{\mathrm{c}}$ Department of Obstetrics \& Gynaecology, Sarojini Naidu Medical College, Agra 282002, India \\ d Department of Community Medicine, Institute of Medical Sciences, Banaras Hindu University, \\ Varanasi 221005, India
}

\section{A R T I C L E I N F O}

\section{Article history:}

Received 2 June 2014

Accepted 24 July 2014

Available online 18 August 2014

Keywords:

Immunization

Maternal determinants

Dropout

Non-adherence

\begin{abstract}
A B S T R A C T
Problem considered: The risk of health problems from vaccine-preventable diseases is highest in those who experience barriers in accessing immunization services. These barriers could be cost, location, lack of awareness of immunization services and their health benefits or other limiting factors.

Material \& methods: The present study was conducted to identify the determinants of complete immunization status among children aged 12-23 months in urban slums of Varanasi in India. A modified WHO EPI cluster sampling method has been used for sample selection. Data on 384 children were collected using pretested questionnaire through house to house visit. Chi-square test, bivariate and multivariate logistic regression were used to assess the factors associated with complete immunization status in the urban slums of Varanasi.

Results: Only $57.03 \%$ children have received the complete recommended immunization schedule under universal immunization program. Significant determinants of the complete immunization were maternal age $(\mathrm{OR}=1.86,95 \%$ CI 1.54-3.23), parity less than three $(\mathrm{OR}=2.84,95 \% \mathrm{CI} 1.98-3.73)$, employment status of mother (OR $=1.39,95 \%$ CI $1.21-2.63)$ and mother's education higher than secondary level ( $\mathrm{OR}=1.59,95 \%$ CI 1.30-2.88). Conclusion: More than half the way is complete to achieve the target of universal immunization against vaccine preventable diseases among children, but there is need to address the issue of dropout. Mother's education, low parity, maternal age and employment status
\end{abstract}

\footnotetext{
* Corresponding author. Tel.: +91522 2494920.

E-mail addresses: cmpandey@sgpgi.ac.in, cmpandeylko@yahoo.com (C.M. Pandey). http://dx.doi.org/10.1016/j.cegh.2014.07.004

2213-3984/C 2014 INDIACLEN. Published by Elsevier B.V. All rights reserved.
} 
of mothers are main factors associated with adherence of immunization schedule. It is necessary that interventions should be strengthened to minimize immunization dropout in the vulnerable children.

(C) 2014 INDIACLEN. Published by Elsevier B.V. All rights reserved.

\section{Introduction}

Vaccination and immunization have been acknowledged as an effective preventive strategy for several communicable diseases. ${ }^{1}$ An immunization campaign carried out by the World Health Organization (WHO) from 1967 to 1977 eradicated the natural occurrence of smallpox. Poliomyelitis is another disease which is going to be eradicated. Since the launch of Global Polio Eradication Initiative by WHO and its partners in 1988, worldwide number of cases of poliomyelitis has fallen by over $99 \%$. In India, number of cases have dropped down from 0.2 million cases per year to 42 cases in year 2010 and polio eradication stage has been achieved during the year 2014.,3 During 1999-2003, deaths due to measles dropped worldwide by almost $40 \%$ and some regions have set a target of eliminating the disease. ${ }^{2}$

India launched Universal Immunization Program (UIP) with the objective to cover at least $85 \%$ of all infants by year $1990 .{ }^{4}$ Further, a national socio-demographic goal was setup in National Population Policy (NPP 2000) to achieve universal immunization against all vaccine preventable diseases by year $2010 .^{5}$

When India became independent sixty years ago, the country's population was a mere 350 million. Since 1947, the growth of population in India is more than threefold while urban population growth has been six folds. ${ }^{6}$ Most of this urban growth is due to rural-urban migration leading to the creation of new slum areas. With the rapid growth of megacities, the risk of outbreak of vaccine preventable disease always exists due to high population density, continuous incursion of a new pool of infective agents with the immigrants and poor coverage of primary immunization in urban slums. ${ }^{4,7,8}$ In many studies, it was shown that mother's knowledge of immunization and vaccination were significantly associated with full immunization. ${ }^{9}$ It was reported in earlier studies that complete age appropriate vaccination was less than $50 \%$ in India, for BCG and OPV age appropriate vaccination was less than $80 \%$ and for DPT and Measles age appropriate vaccination was less than $60 \% .{ }^{10}$ This study was therefore conducted to identify maternal characteristics associated with immunization coverage among children aged 12-23 months in the urban slums of Varanasi, India.

\section{Material and methods}

Varanasi is one of the oldest living cities of India, having more than 200 slums in year 2008 as per records of Varanasi Municipal Corporation. A community based cross-sectional study design has been employed from January 2009 to March 2009 to establish immunization pattern and factors associated to non-adherence to immunization program. The study population consists of mothers of children aged 12-23 months at the time of survey conducted, who were residents of urban slums of the Varanasi.

To identify the determinants of non-adherence of immunization schedule for categorical variables with proportion of $50 \%$ children belongs to either category of possible nonadherence (independent) variable, it was assumed that the baseline probability was 0.6 and alternative probability was 0.8 with $95 \%$ power at $\alpha=0.05$ for two tailed hypotheses, required number of children was 216 , assuming a design effect of 1.5 and $10 \%$ non-response estimated number (216) was escalated to 357 children. ${ }^{11,12}$ Design effect was calculated using the equation.

$D_{\text {eff }}=1+(m-1) \rho$

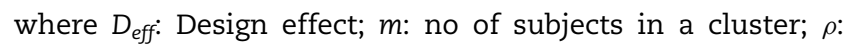
intracluster correlation coefficient.

The sampling procedure of this study was based on the WHO thirty cluster methodology. ${ }^{13}$ In the first phase, thirty urban slum areas of Varanasi were selected randomly from total 228 slums listed in municipal corporation list. In the second stage from each slum area minimum twelve children were included in the study. If in any household more than one child was present all children were included in the study. The first household in each cluster was selected by random walk method, and the rest of them were selected from the contiguous household till the required number of children was attained. Information was collected either from the mother of identified child or head of the household after obtaining a signed informed consent form.

3.

Data collection

To obtain information on the socio-demographic characteristics of mothers, including the mother's knowledge about the immunization program and possible factors of non-compliance or partial immunization, we used a structured questionnaire after pretesting and validation. The universal immunization program in India includes one dose of BCG administered intradermally on the outer upper left arm or shoulder (over the deltoid muscle insertion) at birth, a single dose of measles given subcutaneously on the left upper arm at the age of 9 months, and three doses of $\mathrm{DPT}^{1-3}$ given intramuscularly on the outer mid-thigh at 6, 10 and 14 weeks of ages respectively. 
Table 1 - Socio-economic characteristics of the households.

\begin{tabular}{lcc} 
Variables & $\begin{array}{c}\text { Number of } \\
\text { households }\end{array}$ & $\begin{array}{r}\text { Percentage } \\
\text { distribution }\end{array}$ \\
\hline Monthly income in INR & & \\
$<2000$ & 173 & 28.8 \\
2000-5000 & 288 & 48.0 \\
$>5000$ & 139 & 23.2 \\
Religion & & \\
Hindu & 569 & 94.8 \\
Muslim & 31 & 5.2 \\
Family size & & \\
$<4$ & 161 & 26.8 \\
$4-6$ & 230 & 38.3 \\
6-8 & 120 & 20.0 \\
$>8$ & 89 & 14.8 \\
Sex of head of household & & \\
Male & 558 & 93.0 \\
Female & 42 & 7.0 \\
\hline Note: Total Household (600). & \\
\hline
\end{tabular}

Vaccination status was determined first by examining the vaccination card of the child. In its absence, a history was taken that include a description of the site, and when and how vaccinations were administered. Moreover, an evidence of scar on the skin over the insertion of deltoid muscle on the left upper arm was used as a confirmation of receipt of BCG. A child is defined as "not immunized" if there was no evidence from the card, observation or history. On the other hand, a child is considered as "completed immunization" if there were evidence (by card, observation or history) of administration of all antigens in the schedule (excluding a birth dose of oral polio vaccine) and "partially immunized" if any one of the doses were missing.

\section{Data analysis}

The data obtained was entered and analyzed using SPSS 16.0. Adherence to the recommended schedule was estimated by calculating the proportion of children who completed immunization at 12 months of age. The association between sociodemographic characteristics of the mother and her knowledge of immunization with adherence to immunization has been evaluated using chi-square test. Univariate and multinomial logistic regression analyses were performed with immunization status as dependent variable.

\section{Results}

Table 1 shows the socio-economic characteristics of the households $(n=600)$ included in the study sample. Most of the household (76.8\%) belongs to the income less than five thousand INR per month. Majority of the household follows Hindu religion. In $14.8 \%$ households, more than eight members were found to reside in a household.

There were 384 children aged 12-23 months in total 600 visited household with at least one recently delivered woman. Table 2 reflects the socio-demographic characteristics of the mother of children aged 12-23 months. Most of the women belong to $20-24$ years age group (38.6\%). 41\% women are illiterate whereas only $15 \%$ were educated up-to high school and above. Majority of the women are unemployed or housewife e.g. $85 \%$ and only $11 \%$ are self-employed and $4 \%$ are employed in the sample.

Fig. 1 shows the vaccination time of different antigens amongst children in urban slums of Varanasi. Approximately $80 \%$ of the vaccination was as per scheduled time for all antigens. Adherence to recommended time schedule for immunization was found highest for BCG (approximately $85 \%$ ) and lowest (67\%) for DPT2. Fig. 2 shows the percentage coverage for various antigens among these children. Majority $(92 \%)$ of the children have received BCG. First dose of Polio was received by $83 \%$, second by $75 \%$ and third by only $69 \%$. Similarly, the coverage of DPT 1 was $82 \%$ and $66 \%$ for DPT 3 . The vaccination coverage among the sampled children declined from the first dose to the last dose of antigen and consequently the dropout rate has increased. Out of those 354 children who have received BCG, $10 \%$ have not received Polio $1,18 \%$ have not received Polio 2 and 25\% have not taken Polio 3. Only 59\% children have received Measles vaccination. It is evident from the univariate analysis (Table 3 ) that children were more likely to complete the immunization schedule if their mothers were less than 30 years old (OR $=2.35,95 \%$ CI 1.54-3.57, $p=0.001)$, educated beyond secondary level (OR $=2.67,95 \%$ CI 1.41-5.07, $p=0.002$ ), had maximum two children (OR $=4.36,95 \% \mathrm{CI}$ 2.82-6.74, $p=0.001)$, sex of child is male (OR $=1.53,95 \% \mathrm{CI}$ $1.02-2.30, p=0.03$ ), aware of type of vaccine ( $O R=1.83,95 \%$ CI 1.21-2.77, $p=0.003$ ), aware of benefits of immunization

Table 2 - Socio-demographic characteristics of the responding mothers.

\begin{tabular}{|c|c|c|}
\hline Variables & $\begin{array}{c}\text { Number of } \\
\text { mothers }\end{array}$ & $\begin{array}{l}\text { Percentage } \\
\text { distribution }\end{array}$ \\
\hline \multicolumn{3}{|l|}{ Present age (in years) } \\
\hline Less than 20 & 45 & 11.7 \\
\hline $20-24$ & 148 & 38.6 \\
\hline $25-29$ & 113 & 29.4 \\
\hline $30-34$ & 71 & 18.5 \\
\hline More than 34 & 7 & 1.8 \\
\hline \multicolumn{3}{|l|}{ Education } \\
\hline Illiterate & 156 & 40.9 \\
\hline Primary & 41 & 10.6 \\
\hline Middle & 127 & 33.2 \\
\hline High school \& above & 60 & 15.3 \\
\hline \multicolumn{3}{|l|}{ Employment status } \\
\hline Employed & 17 & 4.4 \\
\hline Self-employed & 42 & 10.9 \\
\hline Unemployment/housewife & 325 & 84.6 \\
\hline \multicolumn{3}{|c|}{ Number of children per respondent } \\
\hline One & 126 & 32.9 \\
\hline Two & 103 & 26.8 \\
\hline Three & 77 & 20.0 \\
\hline Four and above & 78 & 20.3 \\
\hline \multicolumn{3}{|l|}{ Sex of children } \\
\hline Male & 214 & 55.7 \\
\hline Female & 170 & 44.3 \\
\hline
\end{tabular}



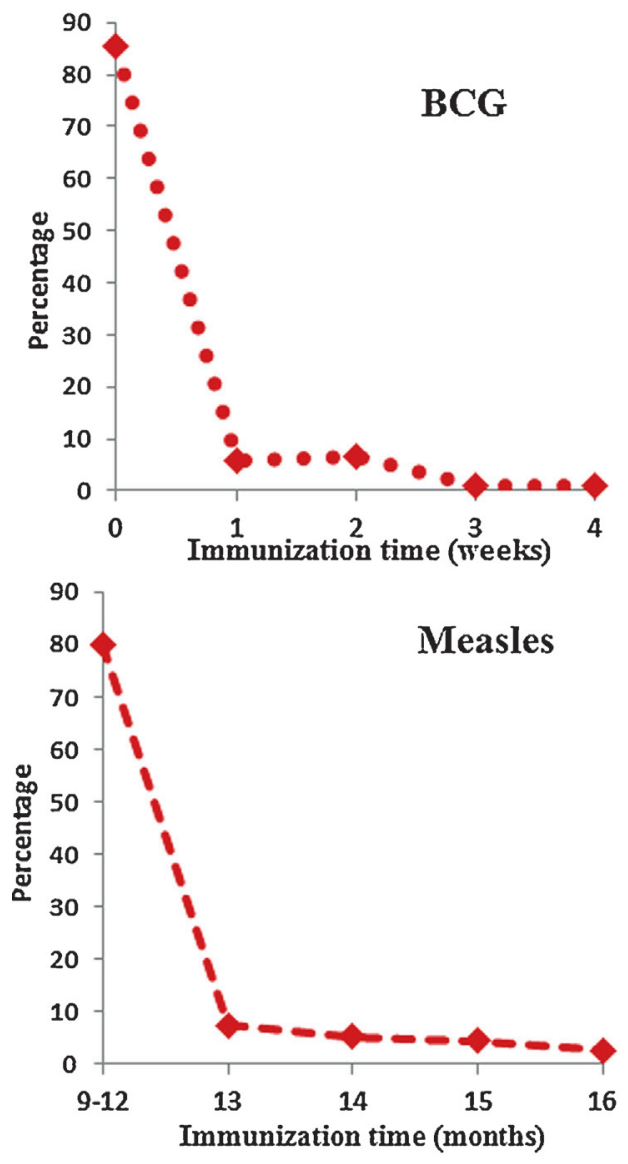
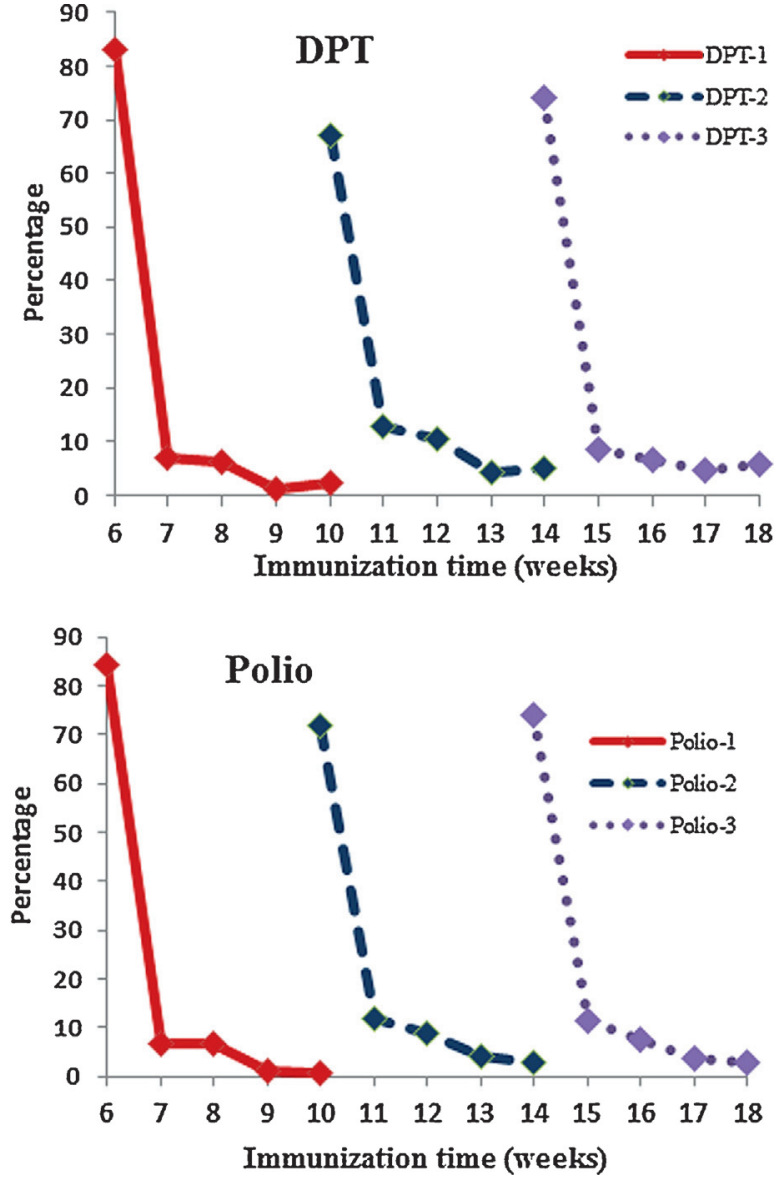

Fig. 1 - Pattern of immunization at various ages of children.

(OR $=1.82,95 \%$ CI 1.21-2.75, $p=0.004)$ and aware of side effects of vaccine $(\mathrm{OR}=2.44,95 \%$ CI 1.52-3.90, $p=0.001)$.

Table 4 shows the result of multivariate logistic regression analysis which revealed that children were more likely to complete the immunization schedule if a mother is less than
30 years of age $(\mathrm{OR}=1.86,95 \%$ CI $1.54-3.23, p=0.02)$, parity less than or equal to two (OR $=2.84,95 \%$ CI $1.98-3.73, p=0.01)$, employed (OR $=1.39,95 \%$ CI 1.2-2.63, $p=0.03$ ) and educated more than secondary level $(\mathrm{OR}=1.59,95 \%$ CI $1.30-2.88$, $p=0.02)$.

\section{Coverage \& Dropout}

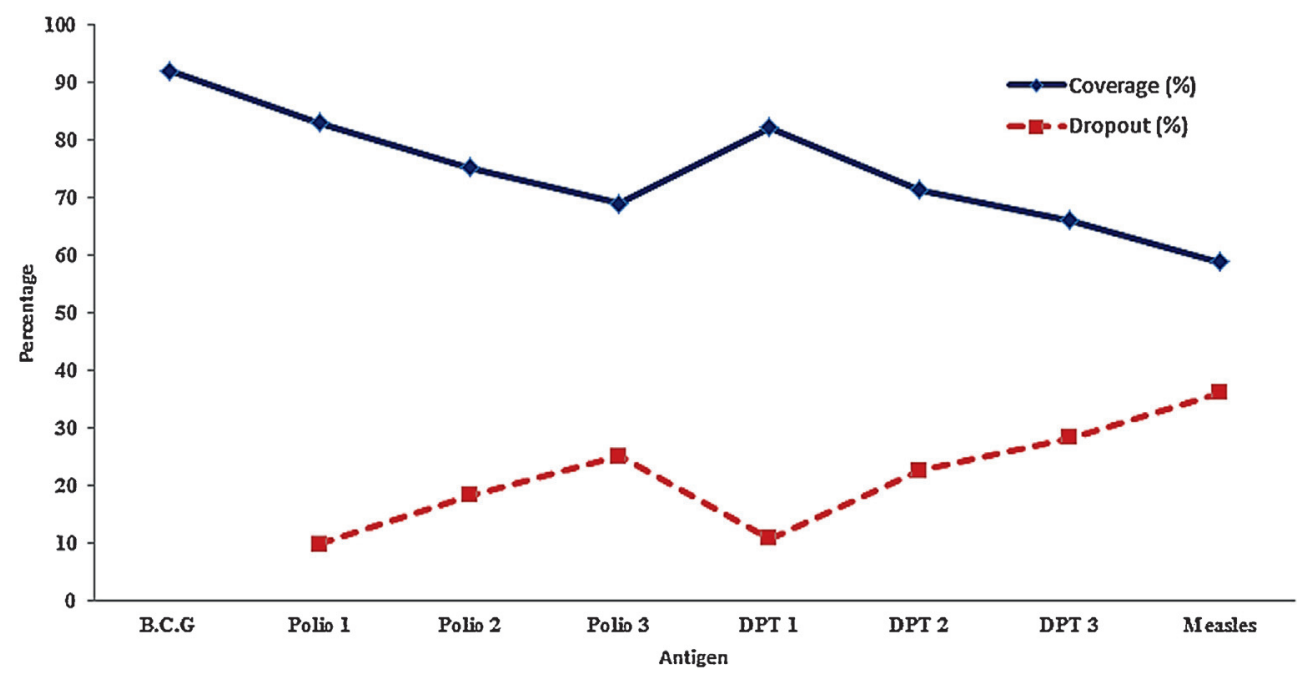

Fig. 2 - Coverage and dropout of various antigens (calculated in comparison with children who received BCG vaccination). 
Table 3 - Association between maternal characteristics and complete immunization $(n=384)$.

\begin{tabular}{|c|c|c|c|c|}
\hline Maternal variables & Fully immunized children & Total children & OR $(95 \% \mathrm{CI})$ & $p$-value \\
\hline \multicolumn{5}{|l|}{ Age of mother (in years) } \\
\hline Less than 30 & 153 & 235 & $2.35(1.54-3.57)$ & 0.001 \\
\hline Greater than or equal to 30 & 66 & 149 & & \\
\hline \multicolumn{5}{|l|}{ Parity of mother } \\
\hline$\leq 2$ & 163 & 229 & $4.36(2.82-6.74)$ & 0.001 \\
\hline$>2$ & 56 & 155 & & \\
\hline \multicolumn{5}{|l|}{ Employment status } \\
\hline Employed & 42 & 59 & $2.06(1.13-3.78)$ & 0.02 \\
\hline Unemployed/housewife & 177 & 325 & & \\
\hline \multicolumn{5}{|l|}{ Education } \\
\hline Post-secondary & 44 & 60 & $2.67(1.41-5.07)$ & 0.002 \\
\hline Primary/secondary & 175 & 324 & & \\
\hline \multicolumn{5}{|l|}{ Sex of the child } \\
\hline Male & 132 & 214 & $1.53(1.02-2.30)$ & 0.03 \\
\hline Female & 87 & 170 & & \\
\hline \multicolumn{5}{|l|}{ Awareness of type of vaccine } \\
\hline Yes & 115 & 177 & $1.83(1.21-2.77)$ & 0.003 \\
\hline No & 104 & 207 & & \\
\hline \multicolumn{5}{|c|}{ Awareness of benefit of vaccine } \\
\hline Yes & 116 & 179 & $1.82(1.21-2.75)$ & 0.004 \\
\hline No & 103 & 205 & & \\
\hline \multicolumn{5}{|l|}{ Awareness of side effects } \\
\hline Yes & 63 & 116 & $2.44(152-3.90)$ & 0.001 \\
\hline No & 156 & 268 & & \\
\hline
\end{tabular}

\section{Discussion}

The problem of dropout has different program related consequences as compared to unimmunized group. It reflects wide gaps in the health care delivery system. The finding of this study indicates that the children living in urban slums belong to the disadvantage subgroup and not availing the benefits of the urban residence. This study suggests high vaccination coverage for vaccines that are given within first few week of birth e.g. 83\%-92\%. But the coverage for measles vaccine, given before the first birthday of the child, was poor with only $58.85 \%$ received this vaccine. This difference is the same in the rest of the studies across the world. ${ }^{14-17}$ High coverage of measles vaccine provides herd immunity thereby decreasing risk for measles exposure and affording

Table 4 - Multivariate logistic regression analysis presenting odds ratio and its $95 \%$ confidence interval for factors associated with complete immunization $(n=384)$.

\begin{tabular}{lccc} 
Variables & OR & $95 \%$ CI & $p$-value \\
\hline $\begin{array}{l}\text { Age of mother (in years) } \\
\text { Less than 30 }\end{array}$ & 1.86 & $1.54-3.23$ & 0.02 \\
$\begin{array}{l}\text { Greater than or equal to 30 } \\
\text { Parity of mother } \\
\leq 2\end{array}$ & 2.84 & $1.98-3.73$ & 0.01 \\
$>2$ & & & \\
$\begin{array}{l}\text { Employment status } \\
\text { Employed }\end{array}$ & 1.39 & $1.21-2.63$ & 0.03 \\
$\begin{array}{l}\text { Unemployed/housewife } \\
\text { Education } \\
\text { Post-secondary }\end{array}$ & 1.59 & $1.30-2.88$ & 0.02 \\
Primary/secondary & & & \\
\hline
\end{tabular}

protection to the small proportion of individuals who are not vaccinated. $^{14}$

Non-adherence to immunization schedule was also a reason of concern in the study population. For all the antigens more than $15 \%$ children were vaccinated after the scheduled time of vaccination which may decrease the efficiency of the vaccine and may not produce fruitful results. It is recommended that BCG be given either at birth or at the time of earliest contact with the child to avoid childhood tuberculosis. Transplacental maternal anti-measles antibodies persist in the child for as long as 9 months. These antibodies protect the child against measles, hence measles usually occurs after 9 months. In the study population $20 \%$ of children were not immunized against measles as per time schedules of universal immunization program which may increase the risk of developing measles.

A great deal of research has been found that factors associated with immunization providers are some of the most significant factors having positive influence on immunization. ${ }^{1,9,18}$ However, the present study focused on maternal characteristics and their knowledge and found that maternal age, maternal employment status, maternal education, parity of mother, were the most important factors influencing complete immunization. The finding that younger mothers were more likely $(\mathrm{OR}=1.86,95 \%$ CI $1.54-3.23, p=0.02)$ to have fully immunized children could be due to the fact that they are likely to have fewer children and are thus selfmotivated to provide care, this has been also supported by the findings of other studies, ${ }^{9,19}$ while few studies have found dis-similar results. ${ }^{20}$ In addition, mothers who were employed had a more chance $(\mathrm{OR}=1.39,95 \%$ CI 1.21-2.63, $p=0.03)$ of having their children immunized than unemployed mothers, this finding appears at same with numerous studies linking maternal employment to a reduction in financial obstacles to vaccination, especially if these obstacles include money and 
transportation. ${ }^{21,22}$ While one author found no relationship between maternal employment and complete immunization of child, many authors have reported inverse relationship between maternal employment and complete immunization of child. $^{9}$ Education was independently associated with complete immunization of the children. Mothers who are secondary or more educated have more probability $(\mathrm{OR}=1.59$, 95\% CI 1.30-2.88, $p=0.02$ ) of having their children immunized than less educated mothers. Educated mothers have been found to better use the knowledge received from health workers during ANC. ${ }^{23}$ Education of mother was found to be significantly correlated with the rate of full immunization in a previous study. ${ }^{4,24}$ Present study suggests that parity less than three increases the chances (OR $=2.84,95 \%$ CI 1.98-3.73, $p=0.01$ ) of a child completing the immunization schedule. This is closely related to the finding of a study concluded that higher birth order was associated with under immunization. ${ }^{4}$ The study concludes that mothers with three or more children may not motivated to provide immunization for the child most recently born. ${ }^{25}$

Studies carried out to identify factors associated with the complete immunization have made recommendations to improve completion rates based on findings. Improvement in mother's knowledge of immunization, interventions aimed at bringing children to immunization centers on time for initial immunization, offering immunization to appropriate locations to reduce travel time, have all been suggested. ${ }^{26}$

\section{Limitations}

The cross-sectional study design that was utilized is less powerful than any analytical design for evaluating risk factors. However because of its relative low cost and simplicity, the methodology has been commonly used and in recent years been extended to health related surveys with different and multiple objectives.

\section{Conclusion}

The finding of the present study revealed a low immunization completion rate among children surveyed and factors identified which are related to mothers that were associated with complete immunization of children in Varanasi slums. The goal of achieving universal immunization, especially in the disadvantaged groups, vulnerable urban slum population with poor health care delivery system, needs more efforts to deal with dropout.

\section{Conflicts of interest}

All authors have none to declare.

\section{Acknowledgment}

Authors are grateful to all the respondents for taking part in the present study. One of author Ashish Awasthi received financial assistance from Indian Council of Medical Research, New Delhi, India.

\section{R E F E R E N C E S}

1. Kahane SM, Watt JP, Newell K, et al. Immunization levels and risk factors for low immunization coverage among private practices. Pediatrics. 2000;105(6):E73.

2. WHO. Immunization against diseases of public health importance. World Health Organ. 2005;288:1-4. WHO Fact Sheet.

3. UNICEF Polio Eradication. India Celebrates Victory over Polio. 2014 Available from: http://www.unicef.org/india/health_3729.htm.

4. Nath B, Singh JV, Awasthi S, Bhushan V, Kumar V, Singh SK. A study on determinants of immunization coverage among 12-23 months old children in urban slums of Lucknow district, India. Indian J Med Sci. 2007;61(11):598-606.

5. MOHFW. National Population Policy 2000. New Delhi: Ministry of Health \& Family Welfare, Govt of India; 2000.

6. ORGI. Census of India. New Delhi: Office of the Registrar General \& Census Commissioner, Ministry of Home Affairs, Govt of India; 2011.

7. Lodha R, Dash NR, Kapil A, Kabra SK. Diphtheria in urban slums in north India. Lancet. 2000;355(9199):204.

8. Loening WE, Coovadia HM. Age-specific occurrence rates of measles in urban, peri-urban, and rural environments: implications for time of vaccination. Lancet. 1983;2(8345):324-326.

9. Fatiregun AA, Okoro AO. Maternal determinants of complete child immunization among children aged 12-23 months in a southern district of Nigeria. Vaccine. 2012;30(4):730-736.

10. Corsi DJ, Bassani DG, Kumar R, et al. Gender inequity and age-appropriate immunization coverage in India from 1992 to 2006. BMC Int Health Hum Rights. 2009;9(suppl 1):S3.

11. Campbell MK, Elbourne DR, Altman DG. CONSORT statement: extension to cluster randomised trials. BMJ. 2004;328(7441):702-708.

12. UNICEF. Coverage Evaluation Survey Report. New Delhi: United Nations Children's Fund; 2009.

13. Malilay J, Flanders WD, Brogan D. A modified clustersampling method for post-disaster rapid assessment of needs. Bull World Health Organ. 1996;74(4):399-405.

14. Mutua MK, Kimani-Murage E, Ettarh RR. Childhood vaccination in informal urban settlements in Nairobi, Kenya: who gets vaccinated? BMC Public Health. 2011;11(1):6.

15. Sharma R, Desai VK, Kavishvar A. Assessment of immunization status in the slums of Surat by 15 clusters multi indicators cluster survey technique. Indian J Community Med. 2009;34(2):152-155.

16. Odusanya OO, Alufohai EF, Meurice FP, Ahonkhai VI. Determinants of vaccination coverage in rural Nigeria. BMC Public Health. 2008;8:381.

17. Chhabra P, Nair P, Gupta A, Sandhir M, Kannan AT. Immunization in urbanized villages of Delhi. Indian J Pediatr. 2007;74(2):131-134.

18. Owais A, Hanif B, Siddiqui AR, Agha A, Zaidi AK. Does improving maternal knowledge of vaccines impact infant immunization rates? A community-based randomizedcontrolled trial in Karachi, Pakistan. BMC Public Health. 2011;11:239.

19. Walburn JN, Pergam JM, Perry SH, Jensen J. Black child care practices in the Midwest. Pediatrics. 1988;82(5):789-790.

20. Danis K, Georgakopoulou T, Stavrou T, Laggas D, Panagiotopoulos T. Socioeconomic factors play a more important role in childhood vaccination coverage than parental perceptions: a cross-sectional study in Greece. Vaccine. 2010;28(7):1861-1869. 
21. Bates AS, Wolinsky FD. Personal, financial, and structural barriers to immunization in socioeconomically disadvantaged urban children. Pediatrics. 1998; 101(4 Pt 1):591-596.

22. Mindlin M, Jenkins R, Law C. Maternal employment and indicators of child health: a systematic review in pre-school children in OECD countries. J Epidemiol Community Health. 2009;63(5):340-350.

23. Kidane G, Morrow RH. Teaching mothers to provide home treatment of malaria in Tigray, Ethiopia: a randomised trial. Lancet. 2000;356(9229):550-555.
24. Vikram K, Vanneman R, Desai S. Linkages between maternal education and childhood immunization in India. Soc Sci Med. 2012;75(2):331-339.

25. Brenner RA, Simons-Morton BG, Bhaskar B, Das A, Clemens JD. Prevalence and predictors of immunization among inner-city infants: a birth cohort study. Pediatrics. 2001;108 (3):661-670.

26. Torun SD, Bakirci N. Vaccination coverage and reasons for non-vaccination in a district of Istanbul. BMC Public Health. 2006;6:125. 